\title{
Dermatology
}

\section{Prevalence of Phototherapy in the Age of Biologics}

\author{
Piergiacomo Calzavara-Pinton ${ }^{\text {a }}$ Arianna Zanca ${ }^{\text {a }}$ Mariachiara Arisi ${ }^{a}$ \\ Maria Teresa Rossi ${ }^{\mathrm{a}}$ Cristina Zane $^{\mathrm{a}}$ Marina Venturini ${ }^{\mathrm{a}}$ Bernhard Ortel $^{\mathrm{b}}$

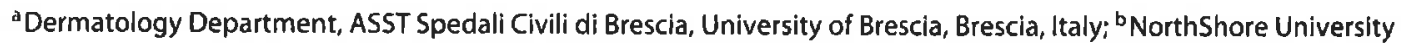 \\ HealthSystem, Skokle، IL, USA
}

\section{Keywords}

Psoriasis - Biologic drugs · Phototherapy · European Medicines Agency

\begin{abstract}
Background: The prevalence of narrow-band ultraviolet $B$ (NB-UVB) use in Europe for moderate and severe psoriasis is unknown, because national registries for psoriasis do not monitor this treatment. Objectives: To quantify the use of phototherapy, biologics or conventional treatments in psoriasis, in a setting where European Medicines Agency (EMA) eligibility criteria for biologics were strictly applied, and phototherapy was included among first-line treatments. Methods: We followed a cohort of 1,090 patients who were referred to the only centre entitled to prescribe biologics and phototherapy during a 5-year period. Resu/ts: The cumulative number of treatment cycles was: 1,047 with NB-UVB phototherapy, 650 with systemic treatments and 239 with biologics; 754 patients received at least 1 course of NB-UVB phototherapy, 422 at least 1 course with a systemic treatment and 137 with a biologic; 595 patients were treated only with phototherapy. Conc/usions: Regular use of NB-UVB as first-line treatment for moderate and severe psoriasis and adherence to the EMA eligibility criteria for biologics led to a relatively restricted use of biologics. (i) 20185 . Karger AG, Basel
\end{abstract}

\section{KARGER}

(c) 2018 S. Karger AG, Basel

\section{Introduction}

Two previous papers $[1,2]$ have discussed the clinical advantages and disadvantages of narrow-band ultraviolet $\mathrm{B}$ (NB-UVB) phototherapy for the treatment of moderate to severe psoriasis "in the age of biologics".

However, its current diffusion is unknown because national registries for psoriasis do not monitor patients treated with non-pharmacological treatments. Moreover, the same registries showed wide differences in the rates of patients treated with the biologics [3-6]. A possible explanation is that the European Medicines Agency (EMA) did not describe in detail the eligibility criteria for biologics and systemic conventional therapies [7-10], and therefore they left a margin of discretion in their interpretation.

The objective of this 5-year cohort study of 1,090 patients suffering from moderate to severe psoriasis without arthritis was to describe treatment allocation under two conditions: (1) NB-UVB phototherapy was evaluated among the first-line treatments for all patients, and (2) EMA criteria for eligibility to biologics were clearly defined and rigorously applied based on the European Guidelines for the treatment of psoriasis [11].

Dr. Moriachiara Arisi

Dermatology Department, ASST Spedali Civili di Brescia, University of Brescia P.Ie Spedali Civili 1

IT-25126 Brescia (ltaly)

t:-Mail mariachiaratarisi@gntail.com 
Table 1. Methods of application of the EMA approval status and regulations of the European Public Assessment Report

\begin{tabular}{ll}
\hline EMA approval status of all biologics & Methods of application \\
\hline Treatment of adults & Age $\geq 18$ years \\
$\begin{array}{ll}\text { With moderate to severe plaque } \\
\text { psoriasis }\end{array}$ & $\begin{array}{l}\text { Cut-off PASI value } \geq 10[10] \\
\text { PASI score was assessed independently by } 2 \text { physicins after attending a PASI training course [3]. } \\
\text { In case of discordance, the } 2 \text { investigators reviewed the scores together wilh a third physician }\end{array}$ \\
\hline Who failed to respond to & $\begin{array}{l}\text { Patients were clinically evaluated at monthly intervals, and they underwent the necessary } \\
\text { laboratory and instrumental tests at baseline and at recommended intervals [10]. We } \\
\text { considered it a treatment failure if an improvement }<\text { PASI50 was attained after } 3 \text { months of } \\
\text { therapy (at the highest recommended dose [10-13] or the highest tolerated dose within the } \\
\text { therapeutic range) or if a patient with an improvement }>\text { PASI50 and }<\text { PASI75 after } 3 \text { months } \\
\text { of therapy did not ameliorate further in spite of another month of treatment. Treatment was } \\
\text { rated as successful and discontinued, if improvement }>\text { PASI90 or improvement }>\text { PASI75 and } \\
\text { no further amelioration despite another month of treatment was achieved }\end{array}$
\end{tabular}

Or who have a contraindication to Absolute contraindications were always considered as exclusion criteria [4-14]. Contraception was suggested for men and women with methotrexate and only for women with acitretin and biologics, and its refusal was considered an exclusion criterion for those therapies [10]

Relative contraindications were carefully evaluated individually, and treatment was not begun if they were not removed or controlled with adequate interventions $[10]$

Drug interactions were carefully evaluated in each individual case. Drugs with possible interactions were removed whenever possible. If the risk was considered too high and the drug could not be withdrawn or substituted, the putative antipsoriatic drug was avoided. Otherwise patients were carefully followed [10]. Motivated patients' refusal of treatment (e.g., time constraint with phototherapy, fear of skin cancer with PUVA therapy or refusal of contraception with methotrexate and acitretin in child-bearing age) were taken into account in the treatment decision

Or are intolerant to Grades 3,4 and 5 or grades 1 and 2 if they were not manageable with minor and temporary drug interventions or a dose reduction within the therapeutic range (Adverse Event Severity Grading Scale based on National Cancer Institute Conmon Terminology Criteria for Adverse Events v4.0) [16]

Other systemic therapy, including cyclosporine, methotrexate or PUVA
Drugs were always prescribed at the highest recommended dose or at the highest tolerated dose if this was within the therapeutic range

In addition, NB-UVB phototherapy was considered among first-line treatment options

Product information for the use of all biologics for psoriasis $[3-5,13]$ in the present study. PUVA, psoralen and ultraviolet $A$ light.

\section{Materials and Methods}

lior further details, see the supplementary material (for all online suppl. material, see www.karger.com/doi/10.1159/000491782) (Fig. 1) (Tables 1, 2) [7-17].

\section{Results}

One thousand ninety patients with moderate or severe plaque-type psoriasis without clinical signs of arthritis were enrolled.

The mean age was 46.1 years (range: $18-89$ years), and the mean age at the onset of psoriasis was $34.7 \pm 17.5$ years. The majority of patients were males (60.1\%), and the skin phototype was I in 20 patients, II in 206, III in 781 , IV in 62 , and $V$ in 21 . The body mass index was $25.0 \pm 4.7$.

The mean Psoriasis Area Severity Index (PASI) score at the first examination was 15.8 (range: 10.1-41.2).

The cumulative number of treatment cycles was 1,936 (Table 3), of which 1,047 (54.1\%) were phototherapy.

Nine hundred and sixteen (87.5\%) treatment cycles with phototherapy were successful whereas 131 (12.5\%) were not, because of lack of efficacy $(82 ; 62.6 \%)$ or rapid relapse after discontinuation $(49 ; 37.4 \%)$. 
Table 2. Adverse Event Severity Grading Scale based on National Cancer Institute Common 'Terminology Criteria for Adverse Events v4.0 [16]

\begin{tabular}{ll}
\hline Grade & Severity \\
\hline 1 & $\begin{array}{l}\text { Mild; asymptomatic or mild symptoms; clinical or } \\
\text { diagnostic observations only; intervention not indicated }\end{array}$ \\
\hline 2 & $\begin{array}{l}\text { Moderate; minimal, local or non-invasive intervention } \\
\text { indicated; limiting age-appropriate instrumental } \\
\text { activities of daily living }\end{array}$ \\
\hline 3 & $\begin{array}{l}\text { Severe or medically significant, but not immediately } \\
\text { life-threatening; hospitalization or prolongation of } \\
\text { hospitalization indicated; disabling; limiting self-care } \\
\text { activities of daily living }\end{array}$ \\
\hline 4 & $\begin{array}{l}\text { Life-threatening consequences or urgent intervention } \\
\text { indicated }\end{array}$ \\
\hline 5 & Death related to adverse event \\
\hline
\end{tabular}

"Instrumental activities of daily living refer to preparing meals, using telephone, managing money, etc. 'belf-care activities of daily living include bathing, dressing and undressing, feeding oneself, as performed by patients who are not bedridden.
Table 3. Combinations of treatments, number of patients and corresponding number of treatment cycles that were delivered to the cohort of 1,090 patients

\begin{tabular}{lrrrr}
\hline \multirow{2}{*}{$\begin{array}{l}\text { Number of } \\
\text { patients }\end{array}$} & \multicolumn{5}{c}{ Number of treatment cycles } \\
\cline { 2 - 5 } & biologic & $\begin{array}{l}\text { conventional } \\
\text { drugs }\end{array}$ & $\begin{array}{c}\text { photo- } \\
\text { therapy }\end{array}$ & total \\
\hline 595 & - & - & 821 & 821 \\
229 & - & 350 & - & 350 \\
63 & 126 & - & - & 126 \\
129 & - & 195 & 184 & 379 \\
10 & 14 & - & 17 & 31 \\
44 & 74 & 71 & - & 145 \\
20 & 25 & 34 & 25 & 84 \\
\hline Total number of & & & & \\
treatment cycles & 239 & 650 & 1,047 & 1,936 \\
\hline
\end{tabular}

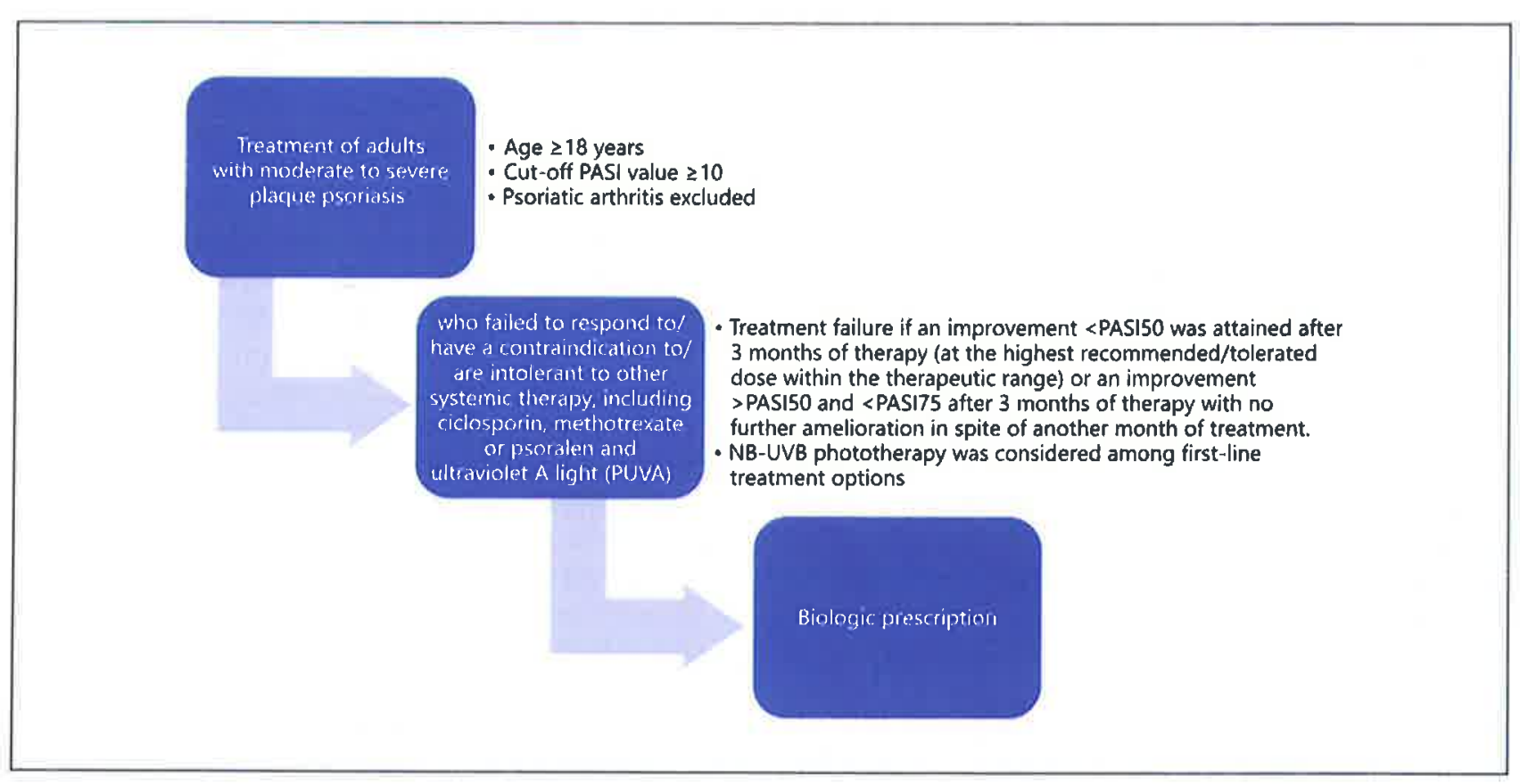

Fig. 1. Flow chart of the Material and Methods. 
Table 4. Therapeutic options that were delivered to patients at subsequent treatment cycles $1-6$

\begin{tabular}{lcccccc}
\hline & Ist cycle & 2nd cycle & 3rd cycle & 4th cycle & 5th cycle & 6th cycle \\
\hline Number of patients & $1,090(100 \%)$ & $445(100 \%)$ & $231(100 \%)$ & $117(100 \%)$ & $43(100 \%)$ & $10(100 \%)$ \\
NB-UVB phototherapy & $714(65.5 \%)$ & $202(45.4 \%)$ & $84(36.4 \%)$ & $35(29.9 \%)$ & $8(18.6 \%)$ & $4(40 \%)$ \\
DMARDs & $300(27.5 \%)$ & $185(41.6 \%)$ & $92(39.8 \%)$ & $50(42.7 \%)$ & $20(46.5 \%)$ & $3(30 \%)$ \\
PUVA & $133(12.2 \%)$ & $68(15.3 \%)$ & $29(12.6 \%)$ & $25(21.4 \%)$ & $11(25.6 \%)$ & $1(10 \%)$ \\
Acitretin & $48(4.4 \%)$ & $41(9.2 \%)$ & $16(6.9 \%)$ & $7(6 \%)$ & $1(2.3 \%)$ & $2(2 \%)$ \\
Cyclosporine & $53(4.9 \%)$ & $38(8.5 \%)$ & $16(6.9 \%)$ & $6(5.1 \%)$ & $4(9.3 \%)$ & $2(20 \%)$ \\
Methotrexate & $66(6.1 \%)$ & $38(8.5 \%)$ & $31(13.4 \%)$ & $12(10.2 \%)$ & $4(9.3 \%)$ & $3(30 \%)^{2}$ \\
Biologics & $76(7 \%)^{2}$ & $58(13 \%)^{2}$ & $55(23.8 \%)^{2}$ & $32(27.4 \%)^{2}$ & $15(34.9 \%)^{2}$ & $1(10 \%)$ \\
Adalimumab & $20(1.8 \%)$ & $23(5.2 \%)$ & $22(9.5 \%)$ & $18(15.4 \%)$ & $7(16.3 \%)$ & $1(2.3 \%)$ \\
Etanercept & $40(3.7 \%)$ & $25(5.6 \%)$ & $10(4.3 \%)$ & $6(5.1 \%)$ & $3(7 \%)$ & $3(2.6)$ \\
Ustekinumab & $9(0.8 \%)$ & $4(0.9 \%)$ & $11(4.8 \%)$ & & & $2(20 \%)$ \\
Infliximab & $2(0.2 \%)$ & $1(0.2 \%)$ & & & & \\
Golimumab & $1(0.1 \%)$ & $1(0.2 \%)$ & & & \\
Secukinumab & $4(0.4 \%)$ & $4(0.9 \%)$ & $12(5.2 \%)$ & $5(4.3 \%)$ & $4(9.3 \%)$ & \\
\hline
\end{tabular}

DMARDs, disease-modifying antirheumatic drugs; PUVA, psoralen plus ultraviolet A. ' 595 patients treated only with NB-UVB phototherapy are part of 754 patients who underwent at least I NB-UVB plototherapy cycle. ${ }^{2}$ Patients who received at least 1 treatment cycle with a biologic were $137: 76,22,21,12,6$ at the $1.5 t, 2$ nd, 3rd, 4 th and 5 th treatment cycles, respectively.

Patients eligible for at least 1 treatment cycle with a biologic agent were $137(12.6 \%)$, and the number of treatment cycles was 239 . In detail, $76,22,21,12$ and 6 patients were deemed eligible to biologics for the first time at the 1 st, 2nd, 3rd, 4th and 5th treatment cycle, respectively. The number of treatment cycles with a biologic was 1 for 72 patients, 2 for 38,3 for 20,4 for 4 and 5 for 3 . The mean duration of treatment with a biologic was (mean $\pm \mathrm{SD}$ ) $13.5 \pm 2.1$ months.

Therapeutic options that were delivered to patients at subsequent treatment cycles are described in detail in 'Table 4 .

The estimated percentage of all psoriatic patients in the centre's service area treated with biologics was $0.53 \%$ in 5 years. The calculation is based on the estimated incidence of psoriasis of $2 \%[3,4]$ in a population of 1.3 million and bearing in mind that ours is the only centre equipped with phototherapy and the only one authorized to prescribe biologics in the area.

The most frequent reason for a decision against the use of acitretin and methotrexate was the presence of at least one absolute contraindication and against PUVA and NB-UVB phototherapy it was the patients' refusal. The main reason for not using cyclosporine was no or poor efficacy at a previous cycle, or the quick relapse after the end of treatment.

\section{Discussion}

NB-UVB phototherapy is a safe and effective treatment option for moderate and severe psoriasis. However, its availability and prevalence in clinical practice are not recorded by registries for psoriasis. In the present prospective cohort study conducted over 5 years, NB-UVB phototherapy was added to the list of conventional treatment options that must be evaluated, before a patient becomes eligible for a biologic drug treatment according to the EMA criteria that were valid until 2017 [7-10, 13-16]. In addition, these criteria were interpreted in detail according to the 2008 European Dermatology Forum guidelines [11] for psoriasis in order to standardize the therapeutic attitude of clinicians as much as possible.

Under these conditions, NB-UVB phototherapy has maintained a very important role in the treatment of moderate and severe psoriasis despite the availability of an increasing array of biological drugs. Indeed, the present cohort of 1,090 patients received $1,047(54.1 \%)$ phototherapy cycles among a total of 1,936 treatment cycles. Nine hundred and sixteen $(87.5 \%)$ were successful, providing a good (at least PASI75) and persistent improvement. Phototherapy was delivered at least once to $754(69.2 \%)$ patients, and 595 of them $(54.6 \%)$ were treated exclusively with 1 or more cycles of phototherapy and never required a systemic conventional or biologic drug.

Dermatology 2018;234:166-172 DOI: $10.1159 / 000491782$ 
This cohort study describes the relevance of phototherapy in the treatment of psoriasis since biologics have become available. Unfortunately, we cannot compare our present results with findings of national registries for psoriasis because these enroll only patients who are treated with systemic treatments and exclude phototherapy.

If we focus on the subgroup of 495 of our 1,090 patients, who would have been included in such a registry, because they had been treated at least once with a systemic therapy, we found that only 137 (27.7\% of this subgroup, $12.6 \%$ of the whole cohort) patients were deemed eligible for a biologic, and they received cumulatively 239 treatment cycles ( $12.3 \%$ of the overall number of treatment cycles). The remaining 358 ( $72.3 \%$ of this subgroup, $32.8 \%$ of the whole cohort) received at least 1 therapeutic cycle with a conventional systemic therapy but never a biologic drug (Table 3).

The present findings demonstrate a relatively restricted use of biologics $27.7 \%$ of patients treated with a systemic drug) in comparison to what is reported by registries of European countries: $63.4 \%$ of enrolled patients in Spain [18], 60\% in the UK [19] and $37.15 \%$ in Germany [20]. The 2008 report of the Italian registry highlighted a $27.2-80 \%$ variability of biologics prescription among different regions [21].

Rates of patients treated with biologics on the estimated overall number of psoriatic patients of the area $[7,8$, 22 ] vary widely: $0.20 \%$ in the UK and Denmark, $0.25 \%$ in Germany, $1.6 \%$ in Sweden [3].

Big differences (more than 14-fold) were reported from 6 Eastern European countries (Bulgaria, Romania, Croatia, Czech Republic, Poland and Hungary), ranging from $0.06 \%$ in Bulgaria to $0.63 \%$ in Hungary [4].

However, direct comparison of these rates is sometimes hampered by different durations of observation: approximately 2 years for the British and German registries, 3 years for the Swedish and Danish registries, 1-2 years for the study from East European countries [4] and 5 years for the present study [3].

In addition, we emphasize that, unlike ours, the results of some cited registers $[3,4,22]$ referred to years before 2010 while the use of biologics has grown in the following years in all European countries $[23,24]$.

One of the possible explanations of these differences can be found in differences in the access to phototherapy.

Indeed, EMA eligibility criteria do not require that NB-UVB phototherapy is delivered before biologics, and therefore phototherapy could be ignored or underused by some centres for a variety of reasons, including insuffi- cient training of medical and nursing staff, the lack of equipment or a shortage of staff to run it.

Also, if a phototherapy centre is not accessible, neither will be PUVA therapy, thus further reducing the number of therapeutic alternatives to be evaluated before a biologic drug is prescribed.

From a clinical perspective, the lack of availability of phototherapy is not an advantage for patients. Indeed, we know that NB-UVB phototherapy is very effective for moderate and severe psoriasis [17] even though randomized comparative studies with conventional systemic and biologic treatments have not been reported so far. With regard to safety, phototherapy has substantial advantages over systemic treatments, such as the absence of systemic toxicity and drug interactions, with the exception of phototoxic drugs. It can also be used for patients with active or latent systemic infection as well as active or previous neoplastic disease. Indeed, for some of these latter patients, it may be the only treatment option.

Comparing the results of the registers we also observed important differences in the relationship between patients who were treated with biologics and patients treated with conventional systemic drugs. One of the possible explanations of these differences lies in a different interpretation or less rigorous application of the EMA criteria. For this reason, in the present study, we tried to reduce interobserver differences of PASI calculation [25], differences in the dosages and durations [11] of first-line treatments before claiming their inefficacy, differences in evaluating relative contraindications, including possible drug interactions [7-10,11,13-15], and differences in the individual evaluation of toxic reactions using a standardized scale [16].

Finally, additional country-specific restrictions to the EMA criteria [4], such as a smaller number of covered biologics, shorter maximum duration allowed for treatment, and more restrictive criteria to be eligible in terms of baseline PASI and Dermatology Quality of Life Index scores could reduce the use of biologics [4].

Obviously, differences in the rate of patients treated with biologics can lead to relevant effects on the total treatment cost for psoriasis. NB-UVB phototherapy and conventional systemic treatments are much cheaper than biologics that cost 10,000-20,000 EUR annually [26] per patient.

In this regard, we would emphasize that a phototherapy equipment can be used to treat dozens of patients at a cost approximating the expense for 1 year of biologic therapy for a single patient [6].
Calzavara-Pinton et al. 
Therefore, increasing rates of patients treated with biologics may raise relevant issues of sustainability of the total expenditure for biologics for psoriasis for the European National Health Systems whereas the availability of phototherapy helps to contain the cost of health spending.

In conclusion, in our experience and supported by the present study, phototherapy remains a mainstay of the management of moderate to severe psoriasis, and about half of our patients were treated with it. In the absence of randomized and controlled comparative studies, we cannot know, if and how much NB-UVB is less effective than systemic treatment options, including biologics. However, its safety profile is very good and allows to treat some patients who could not be treated with any other treatment except for topicals. Moreover, the lack of its availability and a poor interpretation of EMA criteria will likely favour an increased use of biologics with an unjustified increase in health care cost. Obviously, one may question whether the use of phototherapy and the use of EMA criteria of eligibility for biologics that we applied allowed the best treatment option for patients without unwarranted therapeutic restrictions $[27,28]$. Finally, the results of the present study may be useful for comparison with those allowed by the current (after January 2017) setting, where recently changed EMA criteria concerning eligibility for biologics facilitate the access to biologics.

\section{Key Message}

Regular use of narrow-band ultraviolet $B$ as first-line treatment for moderate and severe psoriasis and adherence to the European Medicines Agency eligibility criteria for biologics led to a relatively restricted use of biologics.

\section{Statement of Ethics}

The study followed the principles outlined in the Declaration of Helsinki.

\section{Disclosure Statement}

The authors have no conflicts of interest to disclose.

\section{References}

I Richard EG, Hönigsmamn H: Phototherapy psoriasis, and the age of biologics. Photodermatol Photoimmunol Photomed 2014:30:3 7.

2 Walker D, Jacobe H: Plototherapy in the age of biologics. Psoritsis in the US Medicare population: prevalence, treatment, and factors associated with biologic use. Semin Cu tan Med Surg 2011:30:190-198.

3 Ormerod AD, Augustin M, Baker C, Chosidow O, Cohen AD, Dam "I'N, Garcia-Doval I Lecluse L.L, Schmitt-Egenoli M, Spuls PJ, Watson KD, Naldi L: Challenges for synthesising data in a network of registries for systemic psoriasis therapies. Dermatology 2012; 224:236-243.

4 Rencz L: Kemény L, Gajdícsi J\%, Owczarck $W$, Arenberger P, Tiplica GS, Stanimisovic $A$. Niewada M, Petrova G, Marinov L.I, Kazandhieva I, Péntek M, Brodskey V. Gulácsi L. Use of biologics for psoriasis in Central and Eastern Luropean countries. I Fur Acad Dermatol Venereol 2015;29:2222-2230.

5 Takeshita J, Gelfand JM, Li P, Pinto L, YuX, Rao P, Viswanathan HN, Doshi JA: Psoriasis in the US Medicare population: prevalence, treatment, and factors associated with biologic use. Invest Dermalol 2015;135;2955-2963.

Phototherapy in the Age of Biologics
6 Spandonaro F, Ayala F, Berardesca b, Chi mentis, Girolomoni G, Martini P, peserico $A$, Polistena B, Puglisi Guerra A, Vena GA, Altomare (B, Calzavaria Pinton P: The cost effectiveness of biologic therapy for the treatment of chronic plaque psoriasis in real practice settings in Italy. BioDrugs 2014;28:285-295.

7 EPAR summary of product chanacteristics (Humira) available at http://www.emateuropa.eu/docs/en_..Glidocument_library/ PPAR Product Information/human/ $000481 / W C 500050870$.pdf (lasl accessed )anuary 20, 2017),

8 EPAR summary of product characteristic (Stelna) available at http://www.ema.europa. eu/docs/en_GB/document_library/FPAR Product_Information/human/000958/ WC500058513.pdf (last accessed Jantary 20. 2017).

9 EPAR summary of product characteristics (Remicalde) available at http:/www.ema.europa.eu/docs/en_GiB/document_library/ LPAR__Product_Information/liuman/ $000240 /$ WC 500050888 .pdi (last accessed Jan. uary 20, 2017).

10 EPAR summary of product characteristics (Enbrel) available at htlp://www.ema.curopal. ew/docs/en_GB/document library/LPAR . Product Information/human/000262/ WC500027361.pdi (last accessed January 8 , 2018).
11 Pathirana D, Omerod AD, Saiag P', Reytan N, Saiag P, Smith CH, Spuls P, Rzany B: On the development of European S3-guidelines on the systemic treatment of psoriasis vulgaris. fur Acad Dermatol Venercol 2009;23:5-70.

12 Psoriasis Area and Severily Index (PASI) Iraining. URL:http://pasitraining,com/pasi_ scorc/index,html (last aceessed December I 2011).

13 LPAR summary of product characteristics (Sandimmun Neoral) uvailable at http:// www.ema.europa.eu/ducs/en_GB/docu ment_lilzary/Referrals_document/Sandim mun_Neoral_30/WC500144886.pdf (last accessed January 20, 2017).

14 EPAK summary of product characteristics (Methotrexate) available at bttp://www.emil. curopa,cu/docs/cn_GB/document_library/ liPAR Product lnformation/human/ 003983/WC500213203.pdf (last accessed January 20, 2017).

15 LPAR summary of product characteristics (Acitretin) availible at lottp://www.emacelropa.eu/docs/cn_GB/document_library/Referrals_document/Retinoids_31/Procedure started/WC,500209971.pdf (last accessed Jan(Hary 20, 2017).

$16 \mathrm{htlps} / / \mathrm{evs}$.nci.nih.gov/ftpl/ClCAL/ CICAE_4.03_2010-06 14_QuickReference_ 8.5 11 ,pdf (last accessed January 20, 2017). 
17 Calzavara-Pinton PG, Sala R, Arisi M, Rossi $M T$, Venturini $M$, Ortel B. Synergism between narrowband ultraviolet $B$ phototherapy and etanercept for the treatment of plaque-type psorjasis. Br J Dermatol 2013;169:130-136.

18 Davila-Seijo P, Dauden E, Carretero G, Ferrandiz $C$, Vanaclocha $F$, Gónez-Garcia FJ, Herrera-Ceballos E, De la Cueva-Dobao P, Belinchón I, Sánchez-Carazo JL, Alsina M, López-Estebaranz JL, Ferrán M, Torrado R, Carrascosa JM, Llamas $M$, Rivera $R$, JiménezPuya R, Garcia-Doval I; BIOBADADERM Study Group: Survival of classic and biological systenic drugs in psoriasis: results of the BIOBADERM registry and critical analysis. J Eur Acad Dermatol Venereol 2016;30:19421950.

19 Warren RB, Smith CH, Yiu ZZ, Ashcroft DM Barker JNWN, Burden AD, Lunt $\mathrm{M}, \mathrm{McEl}$ hone $\mathrm{K}$, Ormerod AD, Owen CM, Reynolds NJ, Griffitls CEM: Differential drug survival of biologic therapies for the treatment of psoriasis: a prospective observational cohor study from the British Association of Derma tologists Biologic Interventions Register (BADBIR). I Invest Dermatol 2015;135:26322640.

20 Reich K, Mrowietz U, Radtke MA, Thaci D, Rustenbach SJ, Spehr C, Augustin M: Drug safety of systemic treatments for psoriasis: results from the German Psoriasis Registry PsoBest. Arch Dermatol Res 2015;307:875883.

21 http://www.aifa.gov.it/content/rapport-pso care-2008b (last accessed lune 15, 2017).

22 Bilancio demografico anno 2016 (provviso rio), demo.istat.jt. (last accessed November 11,2016 ).

23 Mitra S: Biologics continue to flare up the psoriasis market, indicating opportunities in the larger dermatology space - DRG blog (last accessed December 28, 2017).
24 World Health Organization: Global report on psoriasis. http://apps. who,int/iris/bitstre im/10665/204417/1/9789241565189_eng. pdf (last accessed December 28, 2017).

25 Oji V, Luger TA: The skin in psoriasis: assess ment and challenges. Clin Exp Rheumatol 2015;33:14-19.

26 Povero M. Pradelli L: Biologic treatments for moderate to severe naive psoriatic patients: a budget impact analysis in Italy. Value Health 2015;18:663-664.

27 Pearce-Smith N: Unwarranted variation: reading list produced by QIPP Right Care. NHS Right Care Essential Reading, 2011. http://www.rightcare.nhs.uk/index.php/category/reading_list/ (last accessed May 8 , 2013).

28 Wennberg JE: Unwarranted variations in healthcare delivery: implications for academic medical centres. Br Med J 2002;325:961964. 
